\title{
openheart Hydroxychloroquine use in COVID-19: is the risk of cardiovascular toxicity justified?
}

\author{
Alex Stevenson (D) , ${ }^{1}$ Ali Kirresh, ${ }^{2}$ Samuel Conway, ${ }^{2}$ Laura White, ${ }^{1}$ \\ Mahmood Ahmad, ${ }^{2}$ Callum Little ${ }^{2,3}$
}

To cite: Stevenson A, Kirresh A, Conway S, et al. Hydroxychloroquine use in COVID-19: is the risk of cardiovascular toxicity justified? Open Heart 2020;7:e001362. doi:10.1136/ openhrt-2020-001362

Received 16 June 2020 Revised 19 July 2020 Accepted 10 August 2020

Check for updates

(c) Author(s) (or their employer(s)) 2020. Re-use permitted under CC BY-NC. No commercial re-use. See rights and permissions. Published by BMJ.

${ }^{1}$ Royal Free London NHS Foundation Trust, London, UK ${ }^{2}$ Cardiology Department, Royal Free London NHS Foundation Trust, London, UK ${ }^{3}$ University College London, London, UK

Correspondence to Dr Callum Little; callumlittle@ nhs.net

\section{ABSTRACT}

The outbreak of COVID-19 in Wuhan, China and its declaration as a global pandemic by WHO has left the medical community under significant pressure to rapidly identify effective therapeutic and preventative strategies. Chloroquine (CQ) and its analogue hydroxychloroquine (HCQ) were found to be efficacious against SARS-CoV-2 when investigated in preliminary in vitro experiments. Reports of success in early clinical studies were widely publicised by news outlets, politicians and on social media. These results led several countries to approve the use of these drugs for the treatment of patients with COVID-19. Despite having reasonable safety profiles in the treatment of malaria and certain autoimmune conditions, both drugs are known to have potential cardiotoxic side effects. There is a high incidence of myocardial injury and arrhythmia reported with COVID-19 infection, and as such this population may be more susceptible to this side-effect profile. Studies to date have now demonstrated that in patients with COVID-19, these drugs are associated with significant QTc prolongation, as well as reports of ventricular arrhythmias. Furthermore, subsequent studies have failed to demonstrate clinical benefit from either drug. Indeed, clinical trials have also been stopped early due to safety concerns over HCQ. There is an urgent need for credible solutions to the global pandemic, but we argue that in the absence of high-quality evidence, there needs to be greater caution over the routine use or authorisation of drugs for which efficacy and safety is unproven.

\section{INTRODUCTION}

Following the initial outbreak of COVID-19 in Wuhan, China and its declaration as a worldwide pandemic, there have been significant efforts to rapidly identify effective therapeutic and preventative strategies. ${ }^{1}$ Several treatments have been proposed and are currently under investigation..$^{2-5}$ Most recently, dexamethasone has been reported to reduce mortality in patients with COVID-19 requiring supplemental oxygen or invasive mechanical ventilation. ${ }^{6}$ There are, however, inherent concerns with regards to the application of drugs for which efficacy and safety has yet to be established. The antimalarial drug chloroquine (CQ) and its analogue hydroxychloroquine (HCQ) have been shown to have antiviral actions against SARS-CoV-2 infection in vitro. ${ }^{7}$ Based on anecdotal experiences and a small number of clinical studies, ${ }^{89}$ these drugs have received widespread media attention. ${ }^{10}$ These early results led to a number of healthcare systems trialling them as treatment for patients with COVID-19 with varying reports of success. ${ }^{11} 12$ The addition of azithromycin (AZT), a macrolide antibiotic, has also been advocated despite limited evidence for its efficacy. ${ }^{2}$ Although HCQ and CQ appear to be safe in the treatment of some autoimmune diseases and malaria, ${ }^{13} 14$ it is unclear if this safety profile can be extrapolated to patients with COVID-19 and specific concerns have been raised over potential cardiovascular toxicity.

\section{MECHANISM OF ACTION OF HCQ AND CQ}

The mechanism underlying the cardiotoxicity of both $\mathrm{HCQ}$ and $\mathrm{CQ}$ is the blockade of the human ether-à-go-go related gene (hERG) potassium channel. ${ }^{15}$ This voltage-gated ion channel mediates the rapid component of the delayed rectifier potassium current, IKr, which is crucial for the repolarisation of cardiac action potentials (figure 1). Therefore, blockade of this channel lengthens ventricular repolarisation which manifests as a prolonged QT interval on the surface ECG. ${ }^{16}$ This may also generate afterdepolarisations through the reactivation of inward calcium depolarising currents, which can trigger premature ventricular contractions, polymorphic ventricular tachycardia and torsades de pointes (TdP). QTc intervals of more than $500 \mathrm{~ms}$ have been demonstrated to increase the risk of TdP events by twofold to threefold ${ }^{17}$ and if sustained can degenerate into ventricular fibrillation and cause sudden cardiac death. ${ }^{18}$ AZT has also been associated with both QTc prolongation ${ }^{19}$ and $\mathrm{TdP}^{20}$; 

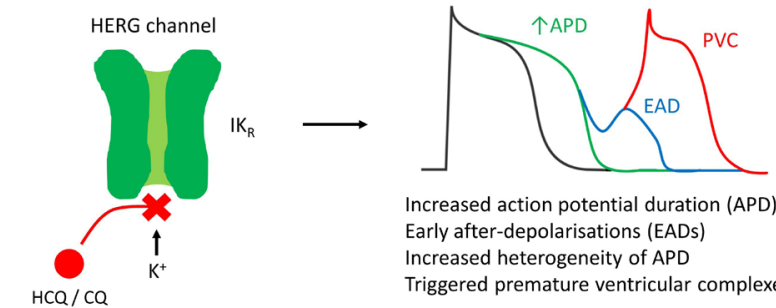

Increased action potential duration (APD) Early after-depolarisations (EADs) Increased heterogeneity of APD

Triggered premature ventricular complexes (PVCs)

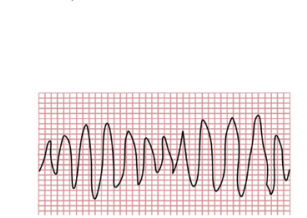

Torsades de pointes

(Polymorphic ventricular tachycardia)

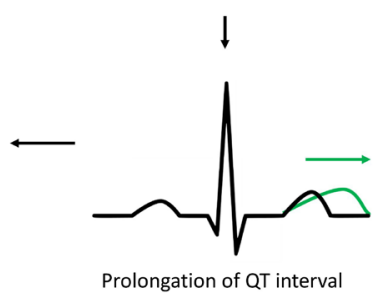

Prolongation of QT interval
Figure 1 Mechanism of cardiotoxicity of hydroxychloroquine (HCQ) and chloroquine (CQ).

therefore, the combination of these agents has been an area of interest. ${ }^{14}$

\section{IS THERE ANY EVIDENCE OF CARDIOTOXICITY?}

Patients with more severe phenotypes of COVID-19 disease, defined by requirement for intensive care support, have a higher incidence of cardiac arrhythmias. ${ }^{21}$ An infrequent but dangerous manifestation of COVID-19 is myocarditis. ${ }^{22}{ }^{23}$ Myocarditis is a proarrhythmogenic condition ${ }^{24}$ and therefore the administration of QTc-prolonging drugs may exacerbate this underlying significant risk of arrhythmia. A retrospective case series of 187 patients with confirmed COVID-19 hospitalised in Wuhan, China showed that an elevated plasma troponin-T level (defined as serum levels above the 99th percentile upper reference limit) was associated with a higher mortality rate $(59.6 \%$ vs $8.9 \%$; $\mathrm{p} \leq 0.001)$ with inflammation proposed as a potential mechanism for myocardial injury. ${ }^{25}$ Interestingly in this study, these patients with an elevated troponin-T level also exhibited a higher incidence of sustained ventricular tachycardia or ventricular fibrillation compared with those with normal levels $(11.5 \%$ vs $5.2 \%$; $\mathrm{p} \leq 0.001)$. Therefore, patients with COVID-19 with evidence of cardiac inflammation appear to be particularly susceptible to arrhythmias.

There is emerging evidence that HCQ or CQ may be independently associated with cardiotoxicity in patients with COVID-19. Studies to date demonstrated that in patients with COVID-19 infection, both $\mathrm{HCQ}^{26}{ }^{27}$ and $\mathrm{CQ}^{27}$ prolong the QTc interval (table 1). Pooled data from the available studies suggest that a significant proportion of patients with COVID-19 (ranging from $11 \%$ to $23 \%$ ) developed QTc intervals greater than 500 ms. ${ }^{11}{ }^{26-30}$ This is known to be associated with a twofold to threefold increased risk of TdP and multiple patients have required discontinuation of treatment due to QTc prolongation. ${ }^{29-31}$ A smaller proportion of patients (ranging from 0\% to 4\%) developed ventricular arrhythmias while on treatment, ${ }^{11} 31$ and there was one reported episode of TdP in the literature. ${ }^{28}$ Given the potential for QTc prolongation and increased risk of ventricular arrhythmia following treatment, it is advised that these medications be initiated in a hospital setting with regular ECG monitoring.

There is some evidence that $\mathrm{CQ} / \mathrm{HCQ}$ cardiotoxicity may be dose dependent. CQ doses in COVID-19 trials have typically involved a loading dose followed by daily doses between 500 and $600 \mathrm{mg}$ and a total treatment duration of 5 days. ${ }^{2831} \mathrm{~A}$ randomised controlled trial by Borba $e t a l^{11}$ evaluating higher doses of CQ underwent an unplanned interim analysis of 81 patients as a result of safety concerns raised by their independent drug and safety monitoring board. This demonstrated that higher doses $(600 \mathrm{mg}$ twice daily for 10 days vs $450 \mathrm{mg}$ twice daily for 1 day then once daily for 5 days) were associated with increased mortality rates and higher rates of patients developing QTc intervals greater than $500 \mathrm{~ms}$ (table 1). It should be noted that the high-dose group were older (54.7 years vs 47.4 years) and had a significantly higher prevalence of pre-existing cardiac conditions including heart failure and coronary artery disease $(17.9 \%$ vs $0 \%)$. These differing population characteristics potentially confound the results and limit any conclusions which can be drawn. Nevertheless, the safety concerns raised by these data led to the immediate interruption of the high dosage arm of this trial.

The combination of HCQ or CQ with AZT has been compared with monotherapy, and studies have shown that this combination of treatment has an augmented effect on the QTc interval (table 1) ${ }^{29} 31$ There is therefore concern that this strategy carries a higher risk of malignant arrhythmias and death and indeed, one patient prescribed this combination developed $\mathrm{TdP}^{31}$

\section{IS IT WORTH THE RISK?}

Despite the initial reported success, ${ }^{2}$ subsequent studies have failed to show any significant benefit of either $\mathrm{CQ}$ or HCQ. Two observational studies of HCQ showed no reduction in either of the primary outcomes of death or the need for mechanical ventilation. ${ }^{330}$ In one study, treatment with HCQ alone was associated with increased overall mortality. ${ }^{12}$ An article that critically appraised the recent literature on the use of CQ or HCQ in the treatment of patients with COVID-19 concluded that the overall methodology was poor and that results were tempered by selection bias and residual confounding bias. ${ }^{32}$ Patient-important outcomes were poorly reported, in particular the incidence of QTc prolongation or cardiac arrhythmia. Included in this was the initial study on which several treatment recommendations were made. In this, it was reported that $600 \mathrm{mg} \mathrm{HCQ}$ daily resulted in significant reduction in viral carriage. ${ }^{2}$ This is a questionable primary outcome as efficacy would be better demonstrated through reduced mortality, reduction in need for mechanical ventilation or reduction in duration of hospital stay. Furthermore, there was no control arm. 
Table 1 QTc prolongation and ventricular arrhythmia or mortality in trials using hydroxychloroquine (HCQ) or chloroquine (CQ) in combination with azithromycin (AZT)

\begin{tabular}{llll}
\hline Study & Drug & Dose & Study \\
\hline Van den Broek et al $^{28}$ & CQ alone & $\begin{array}{l}600 \mathrm{mg} \text { loading dose then } 300 \mathrm{mg} \\
\text { BD for } 5 \text { days }\end{array}$ & 95 \\
& & & \\
Borba et $a l^{11}$ & $\begin{array}{l}\text { High-dose CQ+AZT } \\
\text { Low-dose CQ+AZT }\end{array}$ & $\begin{array}{l}\text { 600 mg BD for 10 days or } \\
\text { 450 mg BD for 1 day then 450 mg BD } \\
\text { for 4 days }\end{array}$
\end{tabular}

\begin{tabular}{|c|c|c|}
\hline Chorin et $a l^{27}$ & $\mathrm{HCQ}+\mathrm{AZT}$ & $\begin{array}{l}400 \mathrm{mg} \mathrm{BD} \text { for } 1 \text { day then } 200 \mathrm{mg} \text { BD } \\
\text { for } 4 \text { days }\end{array}$ \\
\hline Saleh et $a l^{31}$ & $\begin{array}{l}\mathrm{HCQ} \text { or } \mathrm{CQ} \text { alone } \\
\mathrm{HCQ} / \mathrm{CQ}+\mathrm{AZT}\end{array}$ & $\begin{array}{l}\text { HCQ: } 400 \mathrm{mg} \mathrm{BD} \text { for } 1 \text { day then } \\
200 \mathrm{mg} \mathrm{BD} \text { for } 4 \text { days } \\
\text { CQ: } 500 \mathrm{mg} \text { BD for } 1 \text { day then } \\
500 \mathrm{mg} \mathrm{OD} \mathrm{for} 4 \text { days }\end{array}$ \\
\hline
\end{tabular}

\begin{tabular}{|c|c|c|c|c|}
\hline Mercuro et $\left.a\right|^{29}$ & $\begin{array}{l}\mathrm{HCQ} \text { alone } \\
\mathrm{HCQ}+\mathrm{AZT}\end{array}$ & $\begin{array}{l}400 \mathrm{mg} \text { BD for } 1 \text { day then } 400 \mathrm{mg} 0 \mathrm{D} \\
\text { for } 4 \text { days }\end{array}$ & 90 & $\begin{array}{l}\text { Combination therapy associated with } \\
\text { increased QTc prolongation ( } 23 \text { ms vs } 5.5 \\
\text { ms; } p=0.03 \text { ) } \\
\text { QTc }>500 \mathrm{~ms} \text { in } 18 \text { patients }(20 \%) \\
1 \text { episode of TdP } \\
10 \text { patients }(11 \%) \text { discontinued due to QTC } \\
\text { prolongation }\end{array}$ \\
\hline Mahévas et a/ ${ }^{30}$ & $\mathrm{HCQ}$ alone & $600 \mathrm{mg}$ daily & 181 & $\begin{array}{l}\text { No mortality benefit of } \mathrm{HCQ}+\mathrm{AZT} \text { group } \\
\text { vs no HC }(10.7 \% \text { vs } 9.0 \% ; \mathrm{HR} 1.2(0.5 \text { to } \\
3.0)) \\
8 \text { patients ( } 10 \%) \text { discontinued due to QTC } \\
\text { prolongation }\end{array}$ \\
\hline Magagnoli et $a l^{12}$ & $\begin{array}{l}\mathrm{HCQ} \text { alone } \\
\mathrm{HCQ}+\mathrm{AZT}\end{array}$ & Details not reported & 368 & $\begin{array}{l}\text { Increased mortality rates in HCQ group vs } \\
\text { no HCQ }(27.8 \% \text { vs } 11.4 \% ; p=0.03) \\
\text { No mortality benefit of } \mathrm{HCQ}+\mathrm{AZT} \text { group vs } \\
\text { no HCQ }(22.1 \% \text { vs } 11.4 \% ; p=0.72)\end{array}$ \\
\hline Geleris et $a l^{3}$ & HCQ alone & $\begin{array}{l}600 \mathrm{mg} \mathrm{BD} \text { for } 1 \text { day then } 400 \mathrm{mg} 0 \mathrm{D} \\
\text { for } 4 \text { days }\end{array}$ & 1376 & $\begin{array}{l}\text { Outcome of intubation/death unchanged } \\
\text { with HCQ (HR } 1.04 \text { (0.82 to 1.32)) }\end{array}$ \\
\hline
\end{tabular}

BD, twice daily; OD, once daily; TdP, torsades de pointes.

Worryingly, six patients were excluded from the primary analysis, including three patients who were transferred to intensive care and one patient who died. Excluding these patients from the analysis clearly biases the results as it potentially excludes patients with more severe phenotypes. There was no mention on the effects of the drugs on QTc interval or on the incidence of arrhythmia. These criticisms led to an official statement by the International Society for Antimicrobial Chemotherapy that this study did not meet their expected standards. ${ }^{33}$ As a consequence, based on this evidence, the efficacy or safety of these drugs in patients with COVID-19 remains unclear.

Despite the inconclusive and concerning nature of the available evidence, several countries have started to approve the use of HCQ and CQ for the treatment of COVID-19. ${ }^{35}$ The United States Food and Drug Administration (FDA) issued an emergency use authorisation for HCQ and CQ permitting their use in certain hospitalised patients with COVID-19 where clinical trials 
were unavailable or participation was unfeasible. ${ }^{36}$ This was followed by reports of widespread stockpiling of the drugs, which then led to shortages of them for their approved indications. ${ }^{37} 38$

Given the concerns over the proposed routine use of these QTc-prolonging drugs, the Canadian Heart Rhythm Society released a statement emphasising the need for baseline ECGs in hospitalised patients. ${ }^{39}$ It highlighted the need to review and discontinue unnecessary medications which may prolong the QTc interval and also recommended expert consultation in those patients with a QTc greater than $500 \mathrm{~ms}$. A joint statement was also issued by the heads of several American cardiology groups who recognised that these drugs may cause arrhythmias and warned against starting or continuing $\mathrm{HCQ}, \mathrm{CQ}$ or AZT in patients with a QTc greater than $500 \mathrm{~ms}{ }^{40}$

The widespread use of HCQ and CQ was surprising given the lack of convincing data supporting their efficacy in COVID-19. The body of evidence suggesting no benefit and indeed harm was also growing. Support for these drugs began to dwindle following the release of data from a multinational registry analysis on 22 May 2020 by Mehra et al. They reported an increased risk of in-hospital mortality and ventricular arrhythmia associated with the use of HCQ or CQ with or without a macrolide for the treatment of COVID-19. ${ }^{41}$ It was unclear if the increased in-hospital mortality was directly related to their cardiotoxicity; however, it was felt this was plausible given the significant proportion of patients reporting ventricular arrhythmias. This damning data led to the suspension of the chloroquine arm of the WHO Solidarity trial (figure 2). This announcement was followed by controversy as several concerns were raised over the veracity of the primary hospital data and analyses included in the study. An independent third-party peer review was launched, but as they were refused access to the full data set by the company providing the data (Surgisphere Corporation), they were unable to complete this. This led to the retraction of the paper by the authors. ${ }^{42}$

This unfortunate development is concerning and its implications are unclear. Despite this, evidence continues to be published raising further doubt as to the efficacy of these drugs. One study has reported no significant benefit of HCQ as post-exposure prophylaxis for COVID- $19^{43}$ and on 5 June 2020, the chief investigators of the RECOVERY trial have also released a statement announcing that following an interim review of the HCQ arm of their trial, they have decided to stop enrolling participants with immediate effect. ${ }^{44}$ They state that their data "convincingly rules out any meaningful mortality benefit of HCQ in patients hospitalised with COVID-19". Following these results, the United States FDA made to revoke the emergency authorisation of both CQ and HCQ for the treatment of patients with COVID-19. ${ }^{45}$ These are only preliminary data and full results are yet to be released; however, at the time of writing it appears the widespread routine use of these drugs is unjustified and may lead to harm.

HCQ and CQ are chiral compounds currently used as racemates and can be replaced by their single enantiomers in a step called 'chiral switch' ${ }^{46}$ Interactions with drug targets may exhibit stereoselectivity with one enantiomer having differing activity when compared with the other. Perhaps an avenue of future research could look into whether this could attenuate the off-target effect of HCQ and CQ on the hERG potassium channel, thereby improving clinical safety in terms of cardiotoxicity. ${ }^{47}$

\section{CONCLUSION}

We have discussed evidence that raises concerns over the cardiotoxicity of HCQ and CQ. While considered safe to use in other conditions, patients with COVID-19 represent a potentially more vulnerable population. Patients with COVID-19 with myocarditis may be especially susceptible to the cardiotoxic side-effect profile of these drugs. These concerns were significant enough to prompt various national advisory bodies to release warning statements regarding their use. Despite the widespread publicity of these drugs, the evidence at the time for their efficacy was limited and of poor quality. Following the first Hippocratic tenant of non-maleficence, in view of safety concerns that are now being realised, we have to question whether the widespread adoption of these

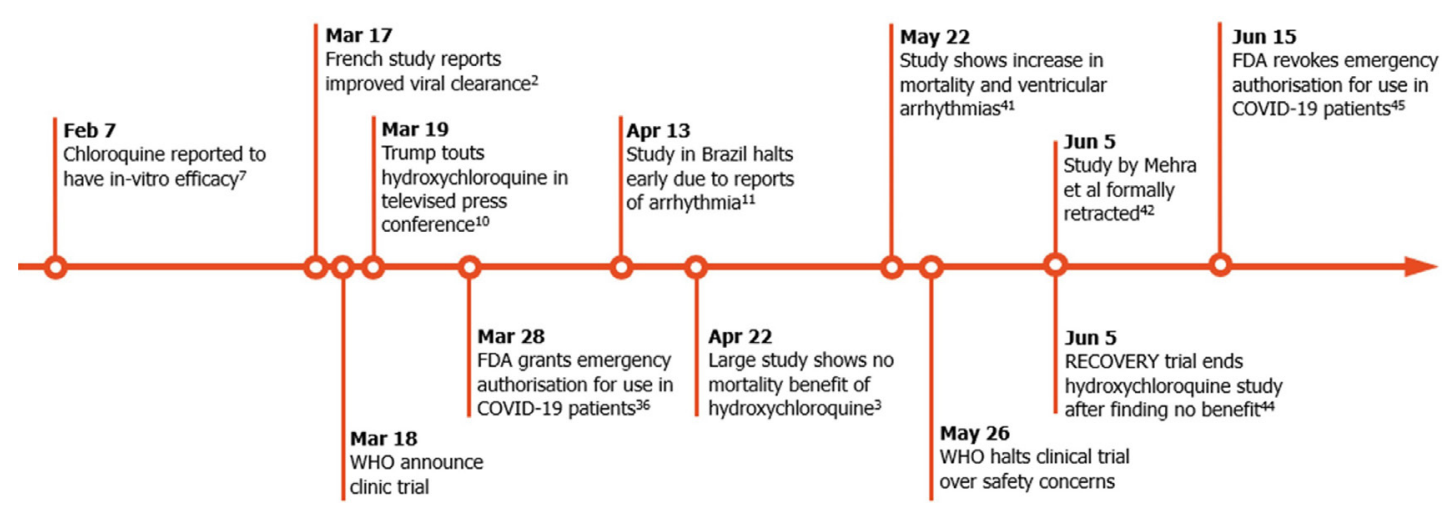

Figure 2 Hydroxychloroquine, chloroquine and COVID-19. A timeline of events. FDA, United States Food and Drug Administration. 
agents in several healthcare systems was justified. Given that subsequent trials have failed to reproduce any of the reported early success in the use of these drugs, it is our opinion that the potential risk of cardiotoxicity is not justified. HCQ and $C Q$ are still being investigated and there is the possibility that enantiomers may be more efficacious and less toxic; however, this is yet to be established. The medical community remains under significant pressure to identify rapid and credible solutions to the global pandemic, but unless there is highquality evidence showing a favourable risk:benefit ratio with adequate reporting of adverse effects, there needs to be greater caution prior to the recommendation of new treatments on an indiscriminate basis.

Contributors All authors contributed to the design and drafting and have approved the final version for publication. AS and AK contributed equally to this paper as joint first authors.

Funding The authors have not declared a specific grant for this research from any funding agency in the public, commercial or not-for-profit sectors.

Competing interests None declared.

Patient consent for publication Not required.

Provenance and peer review Not commissioned; externally peer reviewed.

Data availability statement Data are available in a public, open access repository. All data included in this review article are available in the public domain.

Open access This is an open access article distributed in accordance with the Creative Commons Attribution Non Commercial (CC BY-NC 4.0) license, which permits others to distribute, remix, adapt, build upon this work non-commercially, and license their derivative works on different terms, provided the original work is properly cited, appropriate credit is given, any changes made indicated, and the use is non-commercial. See: http://creativecommons.org/licenses/by-nc/4.0/.

ORCID iD

Alex Stevenson http://orcid.org/0000-0002-0537-1017

\section{REFERENCES}

1 Sanders JM, Monogue ML, Jodlowski TZ, et al. Pharmacologic treatments for coronavirus disease 2019 (COVID-19). JAMA 2020.

2 Gautret P, Lagier J-C, Parola P, et al. Hydroxychloroquine and azithromycin as a treatment of COVID-19: results of an openlabel non-randomized clinical trial. Int J Antimicrob Agents 2020;56:105949.

3 Geleris J, Sun Y, Platt J, et al. Observational study of hydroxychloroquine in hospitalized patients with Covid-19. N Engl J Med 2020;382:2411-8.

4 Cao B, Wang Y, Wen D, et al. A trial of lopinavir-ritonavir in adults hospitalized with severe Covid-19. N Engl J Med Overseas Ed 2020;382:1787-99.

5 Wang Y, Zhang D, Du G, et al. Remdesivir in adults with severe COVID-19: a randomised, double-blind, placebo-controlled, multicentre trial. Lancet 2020;395:1569-78.

6 Horby P, Lim WS, Emberson J, et al. Effect of dexamethasone in hospitalized patients with COVID-19: preliminary report. medRxiv 2020.

7 Liu J, Cao R, Xu M, et al. Hydroxychloroquine, a less toxic derivative of chloroquine, is effective in inhibiting SARS-CoV-2 infection in vitro. Cell Discov 2020;6:16.

8 Tang W, Cao Z, Han M, et al. Hydroxychloroquine in patients mainly with mild to moderate COVID-19: an open-label, randomized, controlled trial. medRxiv 2020.

9 Chen J, Liu D, Liu L, et al. [A pilot study of hydroxychloroquine in treatment of patients with moderate COVID-19]. Zhejiang Da Xue Xue Bao Yi Xue Ban 2020;49:215-9.

10 Karni A, Thomas K. The New York Times. Trump Says He's Taking Hydroxychloroquine, Prompting Warning From Health Experts, 2020. Available: https://www.nytimes.com/2020/05/18/us/politics/trumphydroxychloroquine-covid-coronavirus.html [Accessed 27 May 2020].
11 Borba MGS, Val FFA, Sampaio VS, et al. Effect of high vs low doses of chloroquine diphosphate as adjunctive therapy for patients hospitalized with severe acute respiratory syndrome coronavirus 2 (SARS-CoV-2) infection. JAMA Netw Open 2020;3:e208857.

12 Magagnoli J, Narendran S, Pereira F, et al. Outcomes of hydroxychloroquine usage in United States veterans hospitalized with Covid-19. medRxiv 2020. doi:10.1016/j.medj.2020.06.001. [Epub ahead of print: 21 Apr 2020].

13 Savarino A, Boelaert JR, Cassone A, et al. Effects of chloroquine on viral infections: an old drug against today's diseases? Lancet Infect Dis 2003;3:722-7.

14 Lane JCE, Weaver J, Kostka K, et al. Safety of hydroxychloroquine, alone and in combination with azithromycin, in light of rapid widespread use for COVID-19: a multinational, network cohort and selfcontrolled case series study. medRxiv 2020.

15 Traebert M, Dumotier B, Meister L, et al. Inhibition of hERG K+ currents by antimalarial drugs in stably transfected HEK293 cells. Eur J Pharmacol 2004;484:41-8.

16 Nachimuthu S, Assar MD, Schussler JM. Drug-Induced QT interval prolongation: mechanisms and clinical management. Ther Adv Drug Saf 2012;3:241-53.

17 Sauer AJ, Moss AJ, McNitt S, et al. Long QT syndrome in adults. J Am Coll Cardiol 2007;49:329-37.

18 Tisdale JE. Drug-induced QT interval prolongation and torsades de pointes. Can Pharm J 2016;149:139-52.

19 Russo V, Puzio G, Siniscalchi N. Azithromycin-induced QT prolongation in elderly patient. Acta Biomed 2006;77:30-2.

20 Huang B-H, Wu C-H, Hsia C-P, et al. Azithromycin-induced torsade de pointes. Pacing Clin Electrophysiol 2007;30:1579-82.

21 Wang D, Hu B, Hu C, et al. Clinical characteristics of 138 hospitalized patients with 2019 novel coronavirus-infected pneumonia in Wuhan, China. JAMA 2020;323:1061-9.

22 Inciardi RM, Lupi L, Zaccone G, et al. Cardiac involvement in a patient with coronavirus disease 2019 (COVID-19). JAMA Cardiol 2020;5:819-24

23 Kim I-C, Kim JY, Kim HA, et al. COVID-19-related myocarditis in a 21-year-old female patient. Eur Heart J 2020;41:1859-60.

24 Peretto G, Sala S, Rizzo S, et al. Ventricular arrhythmias in myocarditis: characterization and relationships with myocardial inflammation. J Am Coll Cardiol 2020;75:1046-57.

25 Guo T, Fan Y, Chen M, et al. Cardiovascular implications of fatal outcomes of patients with coronavirus disease 2019 (COVID-19). JAMA Cardiol 2020;5:811-8.

26 Bessière $\mathrm{F}$, Roccia $\mathrm{H}$, Delinière $\mathrm{A}$, et al. Assessment of QT intervals in a case series of patients with coronavirus disease 2019 (COVID-19) infection treated with hydroxychloroquine alone or in combination with azithromycin in an intensive care unit. JAMA Cardiol 2020. doi:10.1001/jamacardio.2020.1787. [Epub ahead of print: 01 May 2020].

27 Chorin E, Dai M, Shulman E, et al. The QT interval in patients with COVID-19 treated with hydroxychloroquine and azithromycin. Nat Med 2020;26:808-9.

28 van den Broek MPH, Möhlmann JE, Abeln BGS, et al. Chloroquineinduced QTc prolongation in COVID-19 patients. Neth Heart $J$ 2020;28:406-9.

29 Mercuro NJ, Yen CF, Shim DJ, et al. Risk of QT interval prolongation associated with use of hydroxychloroquine with or without concomitant azithromycin among hospitalized patients testing positive for coronavirus disease 2019 (COVID-19). JAMA Cardiol 2020. doi:10.1001/jamacardio.2020.1834. [Epub ahead of print: 01 May 2020].

30 Mahévas M, Tran V-T, Roumier M, et al. Clinical efficacy of hydroxychloroquine in patients with covid-19 pneumonia who require oxygen: observational comparative study using routine care data. BMJ 2020;369:m1844.

31 Saleh M, Gabriels J, Chang D, et al. Effect of chloroquine, hydroxychloroquine, and azithromycin on the corrected QT interval in patients with SARS-CoV-2 infection. Circ Arrhythm Electrophysiol 2020;13:6.

32 Alexander PE, Debono VB, Mammen MJ, et al. COVID-19 coronavirus research has overall low methodological quality thus far: case in point for chloroquine/hydroxychloroquine. J Clin Epidemiol 2020;123:120-6.

33 Media MTC. Statement on IJAA paper | International Society of Antimicrobial Chemotherapy. Available: https://www.isac.world/ news-and-publications/official-isac-statement [Accessed 9 Jul 2020].

34 Rathi S, Ish P, Kalantri A, et al. Hydroxychloroquine prophylaxis for COVID-19 contacts in India. Lancet Infect Dis 2020. doi:10.1016/ S1473-3099(20)30313-3. [Epub ahead of print: 17 Apr 2020]. 
35 Multicenter Collaboration Group of Department of Science and Technology of Guangdong Province and Health Commission of Guangdong Province for Chloroquine in the Treatment of Novel Coronavirus Pneumonia. [Expert consensus on chloroquine phosphate for the treatment of novel coronavirus pneumonia]. Zhonghua Jie He He Hu Xi Za Zhi 2020;43:E019.

36 US Food and Drug Administration. Emergency use authorization: coronavirus disease 2019 (COVID-19) EUA information. Available: https://www.fda.gov/emergency-preparedness-and-response/ mcm-legal-regulatory-and-policy-framework/emergency-useauthorization\#covidtherapeutics; [Accessed 27 May 2020].

37 Mehta B, Salmon J, Ibrahim S. Potential shortages of hydroxychloroquine for patients with lupus during the coronavirus disease 2019 pandemic. JAMA Health Forum 2020;1:e200438-9.

38 Peschken CA. Possible consequences of a shortage of hydroxychloroquine for patients with systemic lupus erythematosus amid the COVID-19 pandemic. J Rheumatol 2020;47:787-90.

39 Sapp JL, Alqarawi W, Maclntyre CJ, et al. Guidance on minimizing risk of drug-induced ventricular arrhythmia during treatment of COVID-19: a statement from the Canadian Heart Rhythm Society. Can J Cardiol 2020;36:948-51.

40 Roden DM, Harrington RA, Poppas A, et al. Considerations for drug interactions on QTc in exploratory COVID-19 treatment. Circulation 2020;141:e906-7.

41 Mehra MR, Desai SS, Ruschitzka F, et al. Retracted:

hydroxychloroquine or chloroquine with or without a macrolide for treatment of COVID-19: a multinational registry analysis. The Lancet 2020.

42 Mehra MR, Ruschitzka F, Patel AN. Retraction-

Hydroxychloroquine or chloroquine with or without a macrolide for treatment of COVID-19: a multinational registry analysis. The Lancet 2020.

43 Boulware DR, Pullen MF, Bangdiwala AS, et al. A randomized trial of hydroxychloroquine as postexposure prophylaxis for Covid-19. N Engl J Med 2020;383:517-25.

44 Statement from the Chief Investigators of the Randomised Evaluation of COVid-19 thERapY (RECOVERY) trial on hydroxychloroquine, 2020. Available: https://www.recoverytrial.net/ files/hcq-recovery-statement-050620-final-002.pdf [Accessed 5 Jun 2020].

45 US Food and Drug Administration. Memorandum explaining basis for revocation of emergency use authorization for emergency use of chloroquine phosphate and hydroxychloroquine sulfate. Available: https://www.fda.gov/news-events/pressannouncements/coronavirus-covid-19-update-fda-revokesemergency-use-authorization-chloroquine-and; [Accessed 13 Jul 2020].

46 Tucker GT. Chiral switches. Lancet 2000;355:1085-7.

47 Lentini G, Cavalluzzi MM, Habtemariam S. COVID-19, chloroquine repurposing, and cardiac safety concern: chirality might help. Molecules 2020;25. doi:10.3390/molecules25081834. [Epub ahead of print: 16 Apr 2020]. 